\title{
PENGUATAN PENDIDIKAN KARAKTER MELALUI PENDIDIKAN AGAMA ISLAM DI SMPN 3 BANDAR LAMPUNG
}

\author{
Siti Zulaikah \\ Sitizulaikah@radenintan.ac.id \\ Universitas Islam Negeri Raden Intan Lampung, Indonesia
}

\begin{abstract}
The purpose of this study is to see what kind of character reinforcement can build student character based on Islamic values. This research uses descriptive qualitative research in the field by using observation, interview, group discussion (FGD) data collection techniques and documentation. In addition, data is presented using a descriptive approach, in the form of words, writing, to clarify the data collected and analyzed. The results of the study show that strengthening character education through Islamic education in SMP N 3 Bandar Lampung is divided into 3 fields: class-based KDP, school-based KDP, community-based KDP can be said to be good and not. Class-based KDP has been done well at SMP 3 Bandar Lampung because each stage has been done well. These stages include integrating KDP into the program, KDP through classroom management, KDP through the choice and use of thematic learning methods, KDP by the literature movement, KDP through guidance and counseling. Of the five stages of implementation, it can be said that it is maximized and implemented well. The next field is school culture based on KDP. In school culture, many core KDP values are applied. KDP based on school culture in its implementation went well. The socio-cultural conditions in SMP N 3 Bandar Lampung are very easy to implement, for various types of noble values, so that examples of education can be easily integrated with students. Community-based KDP in its implementation in SMP N 3, Bandar Lampung has not worked in accordance with the KDP concept itself. This is due to the limited scope of its implementation. However, some things can be implemented, including social relations between school committees and parents as key actors in education. There is still limited collaboration, namely the ulama community and the teacher of the Koran. Therefore it can be concluded that among the three KDP fields that have not been properly implemented, it is community based KDP
\end{abstract}

Key Words: Character Education and Islamic Education

\begin{abstract}
Abstrak
Tujuan dari penelitian ini adalah untuk melihat jenis penguatan karakter seperti apa yang dapat membangun karakter siswa berdasarkan nilai-nilai ajaran Islam. Penelitian ini menggunakan penelitian kualitatif deskriptif di lapangan dengan menggunakan teknik pengumpulan data observasi, wawancara, diskusi kelompok (FGD) serta dokumentasi. Selain itu, data disajikan dengan menggunakan pendekatan deskriptif, dalam bentuk kata-kata, tulisan, untuk memperjelas data yang dikumpulkan dan dianalisis. Hasil dari penelitian menunjukkan bahwa penguatan pendidikan karakter melalui pendidikan Agama Islam di SMP N 3 Bandar Lampung dibagi menjadi 3 bidang: PPK berbasis kelas, PPK berbasis sekolah, PPK berbasis masyarakat itu bisa dikatakan baik dan tidak. PPK berbasis kelas sudah dilakukan dengan baik di SMP 3 Bandar Lampung karena setiap tahapan-tahapan telah dilakukan dengan baik. Tahapan-tahapan tersebut termasuk mengintegrasikan PPK ke dalam program, PPK melalui manajemen kelas, PPK melalui pilihan dan penggunaan metode pembelajaran tematik, PPK oleh gerakan literatur, PPK melalui bimbingan dan konsling. Dari kelima tahap implementasi ini, dapat dikatakan bahwa itu maksimal dan dilaksanakan dengan baik. Bidang berikutnya adalah budaya sekolah berdasarkan PPK. Dalam budaya sekolah, banyak nilai inti PPK yang diterapkan. PPK berdasarkan budaya sekolah dalam implementasinya berjalan dengan baik. Kondisi sosialbudaya di SMP N 3 Bandar Lampung sangat mudah diterapkan, untuk berbagai jenis nilai-nilai
\end{abstract}


luhur, sehingga contoh-contoh pendidikan dapat dengan mudah diintegrasikan dengan siswa. PPK berbasis masyarakat dalam implementasinya di SMP N 3, Bandar Lampung belum bekerja sesuai dengan konsep PPK itu sendiri. Hal ini disebabkan oleh keterbatasan ruang lingkup implementasinya. Namun, beberapa hal dapat diimplementasikan, termasuk hubungan sosial antara komite sekolah dan orang tua sebagai aktor kunci dalam pendidikan. Ada Kolaborasi yang masih terbatas, yaitu komunitas ulama dan guru ngaji. Oleh karena itu dapat disimpulkan bahwa di antara tiga bidang PPK yang belum diimplementasikan dengan benar, adalah PPK berbasis masyarakat.

Kata Kunci : Penguatan Pendidikan Karakter dan Pendidikan Agama Islam

\section{PENDAHULUAN}

Saat ini Indonesia sedang dihadapkan pada permasalahan melemahnya karakter bangsa.(Anwar and Salim 2018) Karakter mulia, kesopanan dan religiusitas yang dipertahankan dan menjadi budaya Indonesia selama ini terasa asing dan jarang ditemukan tengah-tengah masyarakat.(Ainiyah 2013) Dalam perkembangannya, pembentukan karakter pada generasi penerus bangsa sudah diupayakan dengan berbagai bentuk dan usaha, namun hingga saat ini belum terlaksana dengan optimal.(Anam 2014) Karakter merupakan suatu ciri khas yang membedakan antara manusia yang satu dengan yang lainnya. Karakter adalah hal dasar yang dimiliki oleh setiap manusia. Pada masa sekarang, banyak kasus kemerosotan karakter yang terjadi di Indonesia. Salah saatunya adalah krisis dalam dunia pendidikan. Banyak peserta didik yang sering membolos, menjamurnya budaya menyontek, kasus tawuran antar pelajar, dan sebagainya. Hal tersebut dikarenakan kurangnya penanaman karakter sejak dini yang dapat dimulai dari lingkungan keluarga, sekolah, dan masyarakat.(Wahyu Suryanti and Dwi Widayanti 2018).

Dunia pendidikan yang secara filosofis dipandang dan diharapkan sebagai alat atau wadah untuk mencerdaskan dan membentuk watak manusia agar lebih baik (humanisasi), sudah mulai bergeser. Hal tersebut terjadi salah satunya disebabkan kurang siapnya dunia pendidikan untuk mengikuti perkembangan zaman yang begitu cepat. Padahal pendidikan seharusnya menjadi alternatif untuk mengatasi dan mencegah krisis karakter bangsa. Oleh sebab itu, diperlukan suatu cara agar pendidikan dapat memperlihatkan tajinya dalam peransertanya membenahi jatidiri bangsa. Saah satu cara yang dilaksanakan dalam beberapa tahun ini yaitu dengan pengembangan pendidikan karakter.(Dahliyana 2017). Kementerian Pendidikan dan Kebudayaan, telah memberlakukan pendidikan karakter di semua tingkat dunia pendidikan formal di 
Indonesia. Pendidikan Karakter adalah upaya mendidik anak supaya mereka dapat membuat keputusan dan mempraktikan secara bijaksana dalam kehidupan sehari-hari, sehingga mereka dapat berkontribusi secara positif terhadap lingkungan mereka (Yetri 2017) yang mengarah pada pencapaian dalam pembentukan karakter dan akhlak mulia siswa secara utuh, terintegrasi dan seimbang, sesuai dengan standar kompetensi.

Sekolah adalah salah satu tempat strategis dalam pembentukan karakter, selain keluarga dan masyarakat. Hal itulah yang mendasari perlu adanya program pendidikan karakter di sebuah sekolah, baik dalam kegiatan intrakurikuler, kokurikuler dan ekstrakurikuler sekolah. Karakter bukan merupakan mata pelajaran yang berdiri sendiri, tetapi nilai nilai karakter tersebut diintegrasikan dalam kurikulum, artinya menjadi penguat kurikulum yang sudah ada, yaitu dengan mengimplementasikan kurikulum yang sudah ada, yaitu dengan mengimplementasikannya dalam mata pelajaran dan dalam kegiatan sehari-hari peserta didik.(Taqiudin Zarkasi 2018). Oleh sebab itu, perlu penanaman pendidikan karakter untuk setiap sekolah dengan berbagai kegiatan yang bisa menunjang penanaman karakter yang baik (Hamid 2017). Diharapkan melalui pendidikan karakter siswa SMP dapat secara mandiri meningkatkan dan menggunakan ilmu pengetahuan mereka, untuk mempelajari dan menginternalisasi dan mempersonalisasikan nilai-nilai karakter dan nilai-nilai moral yang mulia sehingga mereka memanifestasikan dalam perilaku sehari-hari. Pendidikan Karakter di tingkat institusional bertujuan untuk membentuk budaya sekolah yang dipraktikkan oleh seluruh anggota sekolah. Adapun yang dimkasud dengan Budaya sekolah adalah karakteristik, watak, dan citra sekolah yang dipandang di mata masyarakat luas.(Kebudayaan 2010)

Pada pendidikan formal di Kota Bandar Lampung, pendidikan karakter yang diterapkan lebih mengarah pada nilai agama, terutama dalam pendidikan dasar sembilan tahun, terutama di tingkat sekolah dasar dan menengah pertama. Ini dapat dilihat di banyak sekolah negeri dan swasta, yang menanamkan nilai-nilai agama di lingkungan sekolah. Seperti kegiatan sholat Sunah Dhuha sebelum belajar, membaca al-Qur'an, peserta didik perempuang diwajibkan menggunakan jilbab serta pengimpelmentasian kegiata-kegiatan agama lainnya di lingkungan sekolah. Demikian pula, Sekolah Menengah Pertama 3 Bandar Lampung, sudah mengimplementasikan penguatan pendidikan karakter berdasarkan nilai-nilai agama. Mayoritas siswa SMP Negeri 3 
Bandar Lampung adalah Muslim, sehingga kegiatan sekolah harus lebih mengutamakan nilai-nilai agama islam.

Mengingat hasil studi di atas, masih dibutuhan untuk berpikir secara mendalam tentang upaya sekolah untuk mencapai penguatan karakter berbasis Pendidikan Islam. Gerakan pendidikan di sekolah untuk memperkuat karakter melalui proses pelatihan, menstransformasikan, menstransmisikan, dan mengembangkan kemampuan siswa dengan cara menerapkan (1) nilai agama; (2) nasionalis; (3) mandiri; (4) gotong royong; dan (5) integritas merupakan suatu cara penguatan pendidikan karakter di sekolah.

Program Penguatan Pendidikan Karakter (PPK) adalah program yang sangat penting untuk dilaksanakan dengan tujuan memperkuat pendidikan karakter yang dilaksanakan. Selain lingkungan keluarga dan sosial, lingkungan sekolah merupakan institusi nomer dua yang berperan penting dalam pembentukan pribadi anak. Penguatan Pendidikan Karakter merupakan kelanjutan dan revitalisasi gerakan nasional pendidikan karakter yang telah dimulai pada 2010. Penguatan pendidikan karakter (character education) atau pendidikan moral (moral education) dalam masa ini perlu diimplementasikan untuk mengatasi krisis moral yang sedang melanda negeri ini. Krisis tersebut antara lain adalah pergaulan bebas yang semakin meningkat, seperti penyalahgunaan obat-obatan terlarang (narkoba) dan pornografi. Selain dua kasus tersebut, saat ini juga marak terjadi kekerasan terhadap anak dan remaja, pencurian, kebiasaan menyontek, serta tawuran yang sudah menjadi masalah sosial yang sampai saat ini belum dapat diatasi secara tuntas.(Atik Maisaro, Bambang Budi Wiyono 2018)

Hal ini mendorong penulis untuk melakukan penelitian yang lebih lanjut di SMP Negeri 3 Bandar Lampung untuk melihat bagaimana pelaksanaa penguatan pendidikan karakter yang dilaksanakan. Tujuan dari penelitian ini adalah untuk menentukan jenis penguatan karakter apa yang diberikan kepada siswa berdasarkan nilai-nilai agama. Dalam penelitian Peneliti lebih fokus terhadap Pendidikan Agama Islam sebagai sarana pembangunan karakter, sebab dalam pendidikan karakter lebih menekankan niai-nilai agama. Berdasarkan pada studi penelitian terdahulu yang dilakukan oleh EnyWahyu Suryatnti dan Febi Dwi Widayanti dengan judul Penguatan Pendidikan Karakter Berbasis Religius. Pada penelitian terdahulu menyatakan bahwa sudah banyak kasus kemerosotan karakter dalam dunia pendidikan, oleh sebab itu maka dibutuhkan suatu penanaman karakter sejak dini baik dilingkungan keluarga maupun 
dilingkungan sekolah. Penelitian terdauhulu merupakan jenis penelitian kualitatif yang memiliki tujuan untuk mengetahui penerapan pendidikan karakter berbasis religius. Dan hasil temuan dari penelitian terdahulu adalah ada bentuk-bentuk penerapan pendidikan karakter berbasis religius di LPI Kota Malang. Adapun perbedaan pada penelitian penulis dengan penelitian terdahulu adalah penelitian terdahulu fokus pada penguatan pendidikan karakter berbasis religius, sedangkan fokus penelitian penulis adalah lebih fokus terhadap pendidikan islam sebagai upaya pembangunan karakter, sebab dalam pendidikan karakter lebih ditekakan pada nilai-nilai agama.

\section{METODE PENELITIAN}

Penelitian tersebut merupakan penelitian deskriptif kualitatif dengan menggunakan teknik pengumpulan data observasi, wawancara, diskusi kelompok (FGD) dan dokumentasi. Selain itu, dalam penyajian data menggunakan pendekatan deskriptif, dalam bentuk kata-kata, tulisan, untuk memperjelas data yang dikumpulkan dan dianalisis. Dalam penelitian ini, penulis meneliti dan menganalisia dari penguatan pendidikan karakter melalui pendidikan agama Islam di Sekolah Negeri Bandar Lampung 3. Data primer adalah data yang diperoleh oleh peneliti dan sumber utama (Suryabrata, 2003). Diperoleh melalui pengamatan kegaiatan-kegiatan sekolah dan wawancara dengan, kepala sekolah siswa dan pihak lain yang tinggal di sekolah dan orang tua dari siswa. Data sekunder adalah data pendukung yang dapat berupa dokumen atau wawancara. Data sekunder berupa dokumen, profil SMP Negeri 3 Bandar Lampung dan rujukannya, serta hasil narasumber terkait dengan data pendukung lainnya.

Alat pengumpulan data yang digunakan dalam penelitian ini adalah teknik wawancara dengan reponden, yaitu, guru Pendidikan Agama Islam, guru Bimbingan dan Konsling, kepala sekolah, waka siswa, waka kurikulum, dan staf perpustakaan. Alat pengumpulan data berikutnya adalah teknik observasi yang melibatkan mengamati kegiatan pembelajaran guru PAI, kegiatan pendidikan dari awal hingga pulang sekolah, dan kegiatan ekstrakurikuler rohis. Alat pengumpulan data berikutnya adalah mendokumentasikan dokumentasi yang digunakan untuk mengumpulkan dokumen profil sekolah, RPP dan Silabus mata pelajaran PAI. Dan yang terakhir, metode yang 
digunakan dalam pengambilan data dengan teknik FGD. FGD digunakan untuk mengambil data.

Selanjutnya setelah data terkumpul maka data di analisis. Analisis data adalah upaya secara sistematis mengatur catatan yang diperoleh dan hasil wawancara, pengamatan dan data terkait lainnya untuk meningkatkan pemahaman penelitian tentang kasus yang diteliti, dengan memilih yang penting dan yang akan dipelajari, dan yang bisa dikomunikasikan kepada orang lain. Analisis dimulai dengan memeriksa semua data dan sumber yang tersedia, termasuk wawancara, observasi lapangan atau pengamatan, rekaman dan dokumen lainnya.(Moleong 2005)

\section{HASIL DAN PEMBAHASAN}

Dalam Penguatan pendidikan karakter melalui Pendidikan Agama Islam terdapat tiga jalur, yang pertama memperkuat pendidikan karakter berbasis kelas. Berdasarkan data yang diperoleh, SMP 3 Bandar Lampung untuk mata pelajaran Pendidikan Agama Islam menggunakan program K13 di mana program ini merupakan persyaratan dengan memasukkan nilai-nilai karakter. Demikian juga, guru Pendidikan Agama Islam membuat RPP dengan mengggunakan kurikulum 2013. Penguatan ini terdiri dari mengintegrasikan K 13 ke dalam kegiatan pembelajaran PAI, baik intrakurikuler, kokurikuler dan ekstrakurikuler. Nilai-nilai dan pesan-pesan dalam materi pembelajaran diurutkan dan dipilih dan guru menganalisis keterampilan dasar yang dapat dimasukkan dalam rencana pelajaran. Misalnya, RPP kelas IX disiapkan oleh guru PAI dengan tema toleransi pada mata pelajaran PAI. Bahan belajarnya adalah ayat 13 dari Sura Al-Hujurat tentang Toleransi dan menghormari terhadap Perbedaan. Dalam RPP, ada empat keterampilan utama, yaitu K11, K12, K13 dan K14 Semua kompetensi didasarkan pada nilai-nilai karakter dari materi pembelajaran.

Rencana Pembelajaran yang dikembangkan oleh pendidik tentang topik-topik seperti toleransi dan menghormati terhadap keberagaman adalah bentuk integrasi nilainilai penguatan pendidikan karakter, yaitu agama dengan nilai turunan meliputi toleransi dan beriman bertaqwa. Ada dua nilai karakter yang ditanamakan oleh guru dalam sikap toleransi beragama, yaitu toleransi terhadap agama yang sama dan terhadap yang berbeda agama. Peserta didik yang berbeda agama diberi pelajaran agar tidak menghina dan menertawakan agama lain. Peserta didik didorong agar saling 
mengasihi sebagai anak-anak bangsa yang setara, sebagai saudara dan saudari di negara yang sama. Sementara sikap toleransi sesama agama, siswa dididik untuk saling mencintai karena setiap Muslim adalah saudara. Seperti hadis Nabi SAW bahwa persaudaraan umat Islam terlihat seperti bangunan ketika seorang anggota sakit, orang Muslim lainnya merasakan perasaan yang sama. Dengan demikian, tergerak hati dan tubuh untuk ikut merasakan dan membantu sehingga tercipta rasa memiliki dan kasih sayang.

Selain itu, dalam pengembangan rencana pembelajaran dengan materi toleransi dan menghormati perbedaan, penekanannya adalah pada peningkatan karakter dengan menunjukkan pilihan metode pembelajaran dan sumber pembelajaran. Di sini, guru memilih untuk menggunakan model pembelajaran kooperatif. Pembelajaran kooperatif adalah pembelajaran kelompok dengan jumlah siswa 2-5 orang dengan ide-ide untuk memotivasi diri di antara anggotanya sehingga mereka saling membantu untuk mencapai tujuan belajar yang maksimal. Model ini menekankan sikap kerja sama yang baik antar siswa. Dengan kolaborasi ini, akan memupuk kerja sama dan saling membantu, serta fakta bahwa manusia tidak bisa hidup sendiri dan pasti membutuhkan orang lain.

Untuk mendukung pengimplementasian model ini, guru memilih untuk menggunakan metode tanya jawab, wawancara, diskusi, dan bermaina peran. Model tanya jawab terdiri dari penyampaian pesan pendidikan dengan mengajukan pertanyaan dan siswa memberikan jawaban atau sebaliknya, siswa memiliki kesempatan untuk mengajukan pertanyaan dan guru menjawab pertanyaan. Model wawancara adalah model untuk memperoleh informasi dengan mengajukan pertanyaan langsung kepada siswa. Model diskusi adalah sarana untuk menyajikan materi pelajaran ketika guru memberi siswa (kelompok siswa) kesempatan untuk mengadakan pembicaraan ilmiah untuk mengumpulkan pendapat, menarik kesimpulan atau mengatur berbagai solusi untuk memecahkan suatu masalah. Metode role play adalah suatu bentuk model pembelajaran dari game edukasi yang digunakan untuk menjelaskan perasaan, sikap, perilaku dan nilai-nilai, dalam rangka menghargai perasaan, pandangan dan cara berpikir orang lain. Kerja sama, solidaritas, gotong royong dan keluargaan adalah nilainilai yang memperkuat karakter yang diwujudkan. 
Selain itu, RPP juga menjelaskan kegiatan pembelajaran dasar yang menggabungkan nilai-nilai pembangunan karakter. Misalnya, kegiatan literasi terdiri dari melihat, menonton, membaca, dan bermain dalam RPP untuk menumbuhkan sikap mandiri siswa. Siswa harus menjadi pembelajar dan siswa yang disiplin, yang juga diterapkan oleh guru sehingga mereka dapat berpikir kritis dengan mengajukan pertanyaan dan menjadi kreatif dalam menyimpulkan poin-poin penting yang muncul dalam kegiatan pembelajaran. Berpikir kritis memiliki keuntungan menjadi siswa yang tidak memiliki pikiran ceroboh untuk membuat keputusan dan menemukan solusi untuk masalah. Mereka juga dilatih dengan bekerja sama melalui diskusi. Selama diskusi, siswa juga dilatih dalam kemandirian dan kepercayaan diri untuk meneliti dan mengumpulkan informasi dan kemudian menyajikan kembali materi pembelajaran yang sesuai untuk meningkatkan pengetahuan dan keberanian mereka dengan pertukaran informasi antara masing-masing kelompok.

Dalam mengevaluasi, guru melakukan secara otentik berdasarkan kurikulum 2013, yaitu penilaian sikap spiritual, sikap sosial, pengetahuan dan keterampilan yang dimiliki oleh siswa, sehingga menghasilkan penilaian yang objektif. Penilaian autentik adalah ukuran yang mewakili semua nilai sebenarnya yang melekat pada objek yang dievaluasi dalam kaitannya dengan program 2013, objek evaluasi tidak lain adalah siswa. Penilaian otentik tidak hanya mengukur apa yang diketahui siswa, tetapi lebih berfokus pada apa yang dapat dilakukan oleh siswa. Kurikulum13 lebih berfokus pada penilaian sikap. Penilaian sikap dilakukan karena penilaian sikap adalah kegiatan yang bertujuan untuk memahami perilaku peserta didik selama pembelajaran dan pembelajaran eksternal, yang bertujuan untuk menumbuhkan perilaku yang konsisten dengan karakteristik dalam konteks pelatihan karakter siswa. Upaya untuk meningkatkan dan menumbuhkan sikap yang diharapkan sesuai dengan guru KI-1 dan KI-2 harus memungkinkan untuk pembiasaan dan pengembangan berkelanjutan dalam pembelajaran dan pembelajaran eksternal. Untuk mengetahui kemajuan guru harus melakukan penilaian.

Kedua, budaya sekolah. Sekolah telah mengembangkan praktik-praktik baik yang memperkuat nilai religiusitas. Memperkuat nilai pendidikan karakter di sekolah terkait dengan pembiasaan atau budaya di unit pengajaran itu sendiri. Menurut data 
yang diperoleh oleh peneliti, salah satu budaya dari Sekolah Menengah Pertama 3 Bandar lampung adalah budaya berjabat tangan dan menyapa guru, karena budaya $3 \mathrm{~S}$ dibudidayakan dengan sapa, salam, senyum. Lima belas menit sebelum masuk kelas diperharuskan untuk membaca surat dalam Al-Quran dan terjemahannya. Kemudian menyanyikan lagu-lagu Indonesia dan membaca Pancasila. Saat memasuki jam dhuhur, itu wajib untuk sholat dzuhur berjamaah. Dan ketika mereka hendak kembali ke rumah, mereka harus berdoa dilajutkan menyanyikan lagu-lagu wajib dan lagu-lagu daerah. Kebersihan lingkungan juga berlaku untuk Sekolah Menengah Pertama 3 Bandar Lampung dengan menyelenggarakan hari Jumat yang bersih sehingga siswa dapat belajar untuk bekerja sama. Program sekolah juga diselenggarakan, termasuk PHBI, layanan sosial dan buka bersama. Yang sangat diterapkan sekali di SMP 3 Bandar Lampung adalah kewajiban untuk mengenakan jilbab bagi siswi Muslim.

Dan ketiga, memperkuat pendidikan karakter berbasis masyarakat. Dalam hal ini, sekolah tidak banyak berkolaborasi dengan institusi lain. Tetapi dengan budaya nilai-nilai utama religiusitas melalui pendidikan agama Islam, sekolah bekerja sama dengan komunitas ulama. Ini terjadi ketika sekolah mengadakan PHBI, Isro 'dan Mi'roj, Maulid Nabi SAW, Halal-bi Halal, dll. Sekolah mengundang Da'i dari luar untuk mengisi tausiah dalam kegiatan PHBI. Kemudian, dalam kegiatan ekstra kurikuler Rohis, sekolah juga mengundang guru ngaji untuk melatih para siswa agar lancar dalam membaca Al-Quran. Demikian juga, sekolah menggunakan guru yang kompeten untuk melatih siswa untuk membentuk kelompok marhaban.

\section{KESIMPULAN DAN SARAN}

Penguatan pendidikan karakter Di SMP Negeri 3 Bandar dilakukan melalui pendidikan agama Islam. Penguatan pendidikan karakter melalui pendidikan agama Islam ini meliputi tiga jalur dan basis, yaitu berbasis kelas dengan mengintegrasikan $\mathrm{K}$ 13 ke dalam kegiatan pembelajaran PAI, baik intra kurikuler, kokurikuler, dan ekstra kurikuler. Kedua, berbasis budaya sekolah dengan cara membudayakan praktik-praktik yang menguatkan nilai religiusitas. Dan ketiga, berbasis masyarakat, dalam hal ini sekolah masih kurang melibatkan lembaga-lembaga keagamaan untuk bekerjasama dalam mendukung pendidikan karakter. Interaksi kepada orang tua siswa juga masih 
kurang. Begitu juga gerakan literasi keagamaan di lingkungan sekolah dan di luar sekolah juga masih kurang.

Adapun saran dalam peneliitian ini ialah sebagai berikut: pertama, dalam pembelajaran Pendidikan Agama Islam harus terus mengembangkan dan menanamkan nilai-nilai utama, baik dari sisi religiusitas, kemandirian, nasionalisme, gotong royong dan integritas, agar terjadi suatu penguatan dalam pendidikan karakter. Karena dengan pendidikan karakter ini, siswa tidak hanya dituntut untuk memiliki ilmu pengetahuan yang mendalam, tetapi diharapkan memiliki karakter yang sesuai dengan nilai-nilai kehidupan sehari-hari. Terkhusus untuk SMP Negeri 3 Bandar Lampung, untuk lebih fokus pada penguatan pendidikan karakter berbasis masyarakat. Kedua, sekolah harus lebih menekankan nilai agama untuk lebih memperkaya literatur Islam serta meningkatkan dan mengembangkan ilmu pengetahuan keaagamaan. Dan ketiga, perlu dilaksanakan penelitian yang lebih mendalam pada manajemen penguatan pendidikan karakter.

\section{DAFTAR PUSTAKA}

Ainiyah, Nur. 2013. "Pembentukan Karakter Melalui Pendidikan Agama Islam." AlUlum 13 (1): 25-38.

Anam, Much. Arif Saiful. 2014. "Pendidikan Karakter: Upaya Membentuk Generasi Berkesadran Moral" 02 (02): 390-426.

Anwar, Syaiful, and Agus Salim. 2018. "PENDIDIKAN ISLAM DALAM MEMBANGUN KARAKTER BANGSA DI ERA MILENIAL” 9 (2): 233-47.

Atik Maisaro, Bambang Budi Wiyono, Imron Arifin. 2018. "Manajement Program Penguatan Pendidikan Karakter Di Sekolah Dasar." Jurnal Adminitrasi Dan Manajemen Pendidikan 1 (3): 302-12.

Dahliyana, Asep. 2017. "Penguatan Pendidikan Karakter Melalui Kegiatan Ekstrakurikuler Di Sekolah.” Jurnal Sosioreligi 15 (1). 54-64

Hamid, A. 2017. "Pendidikan Karakter Berbasis Pesantren: Pelajar Dan Santri Dalam Era IT \& Cyber Culture.” In , 28. Surabaya: IMTIYAZ.

Kebudayaan, Departemen Pendidikan dan. 2010. "Pembinaan Pendidikan Karakter Di Sekolah Menengah Pertama.” In , 9. Jakarta: Kemendinas.

Moleong, Lexy J. 2005. "Metodologi Penelitian Kualitatif." In , 247. Bandung: PT 
Al-Tadzkiyyah: Jurnal Pendidikan Islam, Volume 10. No. I 2019 P. ISSN: 20869118

E-ISSN: 2528-2476

Remaja Rosdakarya.

Taqiudin Zarkasi, Al Kauseri. 2018. "Penguatan Pendidikan Karakter Di Madrasah (Perpres N0 68 Tahun 2017)” I (3): 1-18.

Wahyu Suryanti, Eny, and Febi Dwi Widayanti. 2018. "PENGUATAN PENDIDIKAN KARAKTER BERBASIS RELIGIUS,” no. September: 254. 